\title{
CNPq E A GENEALOGIA DE UM DESMONTE
}

\author{
Denise de Souza Elias \\ Doutora, Universidade Estadual do Ceará. \\ Bolsista Produtividade em Pesquisa do CNPq - Nível 1A \\ deniseliasgeo@gmail.com
}

O Conselho Nacional de Desenvolvimento Científico e Tecnológico (CNPq) é a principal agência de fomento à pesquisa científica do Brasil e desempenha papel primordial na formulação e na condução das políticas de ciência, tecnologia e inovação. Sua atuação é estruturante para o avanço das fronteiras do conhecimento e, assim, para o desenvolvimento e a soberania do país. Mas tudo isto hoje está em risco, dado o atual contexto político nacional, considerando os cortes no orçamento da instituição, comprometendo a continuidade do papel que a mesma desempenha. O objetivo principal do artigo é alertar para o desmonte do CNPq e da ciência brasileira, através do compartilhamento de inquietações vividas como cientista e cidadã

\section{UM POUCO DE HISTÓRIA}

O CNPq foi criado em 1951 e é a principal agência de fomento à pesquisa do país, desempenhando papel primordial na formulação e na condução das políticas de ciência, tecnologia e inovação desde então. Como principal atribuição tem o fomento à pesquisa científica, tecnológica e à inovação, visando incentivar a formação de pesquisadores brasileiros, contribuindo, assim, para o avanço das fronteiras do conhecimento e soberania nacional.

Concede bolsas para a formação de recursos humanos no campo da pesquisa científica e tecnológica, em universidades, institutos de pesquisa, centros tecnológicos e de formação profissional, tanto no Brasil como no exterior, em todas as áreas do conhecimento, da iniciação científica ao pós-doutorado. Sua atuação contribui para o desenvolvimento nacional e o reconhecimento das instituições de pesquisa e dos pesquisadores brasileiros pela comunidade científica internacional. 
Em poucas décadas, o Brasil teve sua posição melhorada em alguns dos rankings de países que produzem ciência com qualidade no mundo. Isto se deve em grande parte às políticas de fomento à ciência e à tecnologia promovidas pelo $\mathrm{CNPq} \mathrm{e}$ ao empenho de mais de 80 mil pesquisadores brasileiros de todas as áreas. São muitos os exemplos de como a ciência brasileira produz conhecimento e alavanca a economia, transformando conhecimento em riqueza.

Foi a ciência brasileira que descobriu o pré-sal, mesmo que agora ele esteja sendo entregue às petroleiras multinacionais, ou será que alguém ainda tem dúvidas que o massacre contra a Petrobras tinha outro objetivo? Foram as pesquisas do Instituto Tecnológico de Aeronáutica (ITA) junto à Empresa Brasileira de Aeronáutica (Embraer) que transformou o Brasil num dos importantes produtores de aeronaves do mundo, mesmo que agora tudo esteja sendo perdido para a Boeing, entre tantos outros exemplos que poderiam ser dados.

Não são somente as ciências exatas que se destacam, todas as áreas do conhecimento têm sua relevância. Apenas a título de exemplo, poderíamos dizer que os geógrafos brasileiros têm dado imensa contribuição para o estudo da empiricização do tempo no espaço, nas diferentes escalas geográficas; para a compreensão da formação socioespacial brasileira; para o estudo da economia política da urbanização e das cidades; para a compreensão do aumento das desigualdades socioespaciais promovidas pela difusão do agronegócio globalizado, entre outros.

Nesse momento que vivemos uma pandemia de Covid, que já ceifou mais de 600 mil vidas somente no Brasil, a ciência vem dando inúmeras contribuições em tempo recorde, seja com a criação de vacinas, procedimentos de tratamento da doença, evidenciando toda sua importância e potencial.

\section{6: MOMENTO DE INFLEXÃO}

Tudo isto hoje está em risco, dado o atual contexto político nacional, no qual temos convivido com constantes cortes de verba, especialmente desde o golpe parlamentar travestido de impeachment da Presidenta Dilma Rousseff em 2016, 
comprometendo a continuidade do papel que o CNPq desempenha há décadas de forma tão importante.

O orçamento do CNPq está em queda brutal desde o golpe de 2016. Isto se reflete na diminuição de editais, no não aumento do número e no valor das bolsas etc. Importante dizer que há anos o número de bolsas é muito inferior à demanda das áreas, especialmente considerando a velocidade do crescimento da pós-graduação nas duas últimas décadas.

Isto significa que a ciência e as universidades públicas brasileiras estão em risco. E a considerar o panorama político atual, especialmente as ciências humanas, as sociais aplicadas, a educação e as artes que, de maneira geral, sempre sofrem mais com os cortes, por serem consideradas não prioritárias para o desenvolvimento do país e especialmente agora, com o novo grupo à frente do executivo federal, que elegeu tais setores como as verdadeiras "bruxas modernas".

Os retrocessos políticos desde 2016, que se agravam ainda mais com a posse do atual presidente da República, Jair Messias Bolsonaro (01/01/2019 - ), têm promovido um processo de desmonte do sistema de financiamento da pesquisa no Brasil. O cenário atual é de grave crise e cortes de orçamento no $\mathrm{CNPq}$, o grande último no início de outubro do presente ano, quando por interferência do ministro da Economia Paulo Guedes (01/01/2018- ), com uma só canetada, houve o corte de percentual significativo das verbas do $\mathrm{CNPq}$, comprometendo toda a base de sustentação da instituição e, por consequentemente, do ensino superior público, que efetivamente está ameaçada.

As políticas de fomento à educação, à ciência e à tecnologia refletem as escolhas políticas dos governos e, desta forma, dada a total falta de visão estratégica do atual, estamos efetivamente andando para trás e os avanços conseguidos pela área de CT\&I vêm sendo dia a dia desestabilizados.

Tudo que vivenciamos me leva a apresentar para os leitores uma hipótese preocupante. Qual seria esta hipótese? A de que, mais do que cortes de verba para a pesquisa científica, estaria havendo quase um desmonte do CNPq. Quero dizer com isto que os cortes não afetam somente as bolsas, os financiamentos à pesquisa, mas 
todo o funcionamento da instituição, como se a mesma estivesse sendo aos poucos corroída por dentro.

Estamos vivendo uma democracia rasurada. Outros neologismos ou metáforas poderiam ser utilizados para o caso do CNPq, ou seja, não é que ele deixou de existir, ele continua, mas ações e processos importantes estão sendo comprometidos, como se aos pouquinhos estivessem corroendo alguns dos pilares da instituição. Acredito que estes são sólidos, construídos ao longo de seus 70 anos, e ainda é tempo de parar estes processos, até por isso insisto na hipótese visando o debate sobre o tema e a mobilização da sociedade como um todo e não só a científica.

\section{O FUTURO ESTÁ EM RISCO}

Não tenho dúvidas de que a graduação e a pós-graduação das universidades públicas serão rapidamente impactadas por todos estes processos. Estamos vivenciando dois movimentos que vão em sentidos opostos: o número de cursos e alunos da graduação e da pós-graduação cresceu muito nas últimas duas décadas e a verba para financiamento da pesquisa está em queda abrupta.

Penso que todos já estamos sentindo o que tudo isto significa no nosso cotidiano: encolhimento da pesquisa pura e da aplicada, da pesquisa em rede; diminuição da cooperação e da mobilidade acadêmica; redução dos convênios e acordos bilaterais; decréscimo da interdisciplinaridade; restringimento da desconcentração da produção do conhecimento; comprometimento da formação de recursos humanos na graduação e na pós-graduação; minoração das possibilidades de influenciar políticas públicas etc.; emigração de cientistas, na contramão do que ocorria nos últimos quinze ou vinte anos.

Diante do quadro, parece-me que o mais importante agora é olhar para frente, é pensar o futuro. Os desafios que sempre foram grandes estão ainda maiores.

Como em outras áreas, tal como na Previdência, não se trata de falta de recursos, mas de escolhas políticas, de vontade política e, talvez, como tudo vem demonstrando, também de falta de visão estratégica e de conhecimento de como fazer. Mas, não se enganem, o propósito de todos os ataques ao ensino e à pesquisa públicos 
é, sem sombra de dúvida, o projeto do atual governo de acabar com as universidades públicas no país. Sem elas, não há nenhuma chance de algum dia termos diminuída nossa histórica desigualdade socioespacial.

É hora de repensar as estratégias de ação para o futuro, mas o futuro que já começa após a leitura desta oração, e lutar para que o financiamento à educação e à pesquisa científica seja público e parte de uma política de Estado e que não possa sofrer intervenções radicais a cada novo governo, como está acontecendo agora, que colocam em risco a sobrevivência de todo o sistema de ensino e pesquisa públicos, construído ao longo de décadas.

Nenhuma sociedade se constrói sem conhecimento, sem educação, sem ciência, sem pesquisa, que são pilares estruturais do desenvolvimento econômico e social. Somo-me aos que defendem que gastos com ensino e pesquisa, ciência e tecnologia não constituem despesa, mas investimento, muito diferente do que costumam entender os que estão à frente das áreas econômicas e, por mais inusitado que seja, opinião compartilhada pelo nosso atual ministro da Educação, que considera que "universidade não é para todos".

Uma rápida pesquisa sobre o tema mostrará que são inúmeros os países que investiram suas maiores somas nestes setores exatamente nos momentos de piores crises econômicas e não o contrário. Isto porque as despesas em educação, ciência e tecnologia ampla e rapidamente se replicam, direta e indiretamente, na dinamização da economia, além de se constituírem no sustentáculo de todo país, por gerações.

Neste momento, precisamos pensar em algumas frentes de atuação visando reverter o quadro vigente. Citemos ao menos duas, uma mais específica, da comunidade científica e uma mais geral, da sociedade como um todo. São várias as vozes que têm afirmado que é importante que a sociedade melhor compreenda o que significam as universidades públicas e a pesquisa científica para o país. Enquanto isto não ocorrer será difícil ter o apoio da sociedade como um todo, que continuará acreditando nas fake news que têm se replicado pelas redes sociais, muitas delas inclusive a partir do próprio grupo de apoio do atual governo federal. 
Uma coisa é certa, é hora de nos reinventarmos. Devemos entender que estamos terminando uma fase, um momento da política, da história, da economia, da pesquisa e uma nova está começando e não temos certeza de qual contorno terá. Mas isto vai depender muito da nossa força de reivindicação. Temos que lutar para defender a universidade pública, a pesquisa e a ciência brasileiras.

Termino destacando que precisamos estabelecer nossas estratégias de ação, pois sem elas não vamos chegar a lugar algum. Entendo que a metodologia científica serve para qualquer coisa na vida. Assim, está na hora de construirmos nosso projeto para enfrentar a nova realidade: estabelecer nossos objetivos, quais procedimentos para atingi-los e assim por diante. E este sim, deve ser um projeto em rede, que una a todos nós, com todas as áreas do conhecimento de mãos dadas, como de resto com toda a sociedade brasileira.

O papel dos sindicatos, das entidades e das associações profissionais devem também ter papel primordial neste contexto. Só assim teremos alguma chance de reter os retrocessos do presente e desatar os nós que significam entraves para avançarmos na construção da emancipação social e da democracia, que estão bastante ameaçadas.

Caso contrário, direitos conquistados depois de décadas de luta pela sociedade continuarão sendo moeda de troca no balcão de negócios dos governos, com o incremento da reestruturação produtiva, do ultraneoliberalismo, sob o comando do capital financeiro, com o acirramento das desigualdades socioespaciais, dos conflitos e da fome, no campo e nas cidades.

É o futuro que está em jogo. 